\title{
Vital Signs: Dental Sealant Use and Untreated Tooth Decay Among U.S. School-Aged Children
}

\author{
Susan O. Griffin, $\mathrm{PhD}^{1}$; Liang Wei, MS ${ }^{1}$; Barbara F. Gooch, DMD²; Katherine Weno, DDS ${ }^{1}$; Lorena Espinoza, DDS ${ }^{1}$
}

On October 18, 2016, this report was posted as an MMWR Early Release on the MMWR website (http://www.cdc.gov/mmwr).

\section{Abstract}

Background: Tooth decay is one of the greatest unmet treatment needs among children. Pain and suffering associated with untreated dental disease can lead to problems with eating, speaking, and learning. School-based dental sealant programs (SBSP) deliver a highly effective intervention to prevent tooth decay in children who might not receive regular dental care. SBSPs benefits exceed their costs when they target children at high risk for tooth decay.

Methods: CDC used data from the National Health and Nutrition Examination Survey (NHANES) 2011-2014 to estimate current prevalences of sealant use and untreated tooth decay among low-income ( $\leq 185 \%$ of federal poverty level) and higher-income children aged 6-11 years and compared these estimates with 1999-2004 NHANES data. The mean number of decayed and filled first molars (DFFM) was estimated for children with and without sealants. Averted tooth decay resulting from increasing sealant use prevalence was also estimated. All reported differences are significant at $\mathrm{p}<0.05$.

Results: From 1999-2004 to 2011-2014, among low- and higher-income children, sealant use prevalence increased by 16.2 and 8.8 percentage points to $38.7 \%$ and $47.8 \%$, respectively. Among low-income children aged $7-11$ years, the mean DFFM was almost three times higher among children without sealants (0.82) than among children with sealants. Approximately 6.5 million low-income children could potentially benefit from the delivery of sealants through SBSP.

Conclusions and Implications for Public Health Practice: The prevalence of dental sealant use has increased; however, most children have not received sealants. Increasing sealant use prevalence could substantially reduce untreated decay, associated problems, and dental treatment costs.

\section{Introduction}

National data from 1999-2004 indicate that by age 19 years, approximately one in five children have untreated tooth decay (1). Children living in poverty are more than twice as likely to have untreated decay $(27 \%)$ than are children in families whose income exceeds $200 \%$ of the federal poverty level (FPL) (13\%). Untreated tooth decay can lead to pain and infection, resulting in problems with eating, speaking, and learning (2). Approximately $16 \%$ of children living in poverty were reported by a parent to have had a toothache within the last 6 months (3). A recent multivariate analysis also found that children with poor oral health miss more school days and receive lower grades than children with good oral health (4).

Approximately $90 \%$ of tooth decay in permanent teeth occurs in the chewing surfaces of the back teeth (5). Much of this decay could be prevented with the application of dental sealants. Sealants are plastic coatings applied to the pits and fissures in tooth surfaces to prevent decay-causing bacteria and food particles from collecting in these hard-to-clean surfaces.
Studies on sealant effectiveness indicate that sealants delivered in clinical or school settings prevent about $81 \%$ of decay at two years after placement, $50 \%$ at four years and can continue to be effective for up to 9 years through adolescence (G); no clinically significant adverse effects have been associated with receipt of sealants $(\sigma)$. Sealants are underused, especially among low-income children who have the highest risk for decay. National data from 1999-2004 indicated the prevalence of sealant use among children aged 6-11 years living in poverty was $21 \%$ compared with $40 \%$ among children from families with incomes $>200 \%$ of the FPL (1). Increasing sealant use prevalence is a national health goal $(7)$ and the National Quality Forum* has endorsed dental care performance measures aimed at increasing sealant use prevalence in children at elevated risk for tooth decay (8).

School-based sealant programs (SBSP) typically deliver sealants in schools attended by a large number of children participating in the free/reduced-price meal program (i.e., family

\footnotetext{
*http://www.qualityforum.org/Home.aspx.
} 


\section{Key Points}

- Tooth decay is one of the most common chronic diseases of childhood. If left untreated, tooth decay can have serious consequences including problems with eating, speaking, and learning.

- Two years after placement, dental sealants prevent $>80 \%$ of cavities in the permanent molars, in which nine in 10 cavities occur. Most children, however, do not have dental sealants, especially children from lowincome families. These children are twice as likely as higher-income children to have untreated tooth decay.

- Providing sealants through school-based programs is an effective way to increase sealant use. The benefits of school-based dental sealant programs exceed their cost when they serve children at high risk for tooth decay. The programs become cost-saving after 2 years and save $\$ 11.70$ per sealed tooth over 4 years.

- In this study, approximately $60 \%$ of children aged 6-11 years from low-income families (approximately 6.5 million children), did not have dental sealants. Although sealant prevalence during the last decade increased by $72 \%$ among low-income children, these children were still $20 \%$ less likely than children from higher-income families to have dental sealants. Children without sealants had almost three times more cavities in permanent first molars compared with children with sealants.

- Providing sealants to the approximately 6.5 million low-income children who currently do not have them would prevent 3.4 million cavities over 4 years.

- Additional information is available at http://www.cdc. gov/vitalsigns.

income $\leq 185 \%$ of the FPL) ( 6 ). The Community Preventive Services Task Force ${ }^{\dagger}$ (Task Force) recommends SBSP, on the basis of strong evidence that these programs prevent tooth decay and increase the number of children receiving sealants at schools (G). A second, systematic review of economic evaluations of SBSP conducted for the Task Force found that the benefits of SBSP exceed their cost when they serve children at high risk for tooth decay, becoming cost-saving after 2 years (G) and saving $\$ 11.70$ per tooth sealed over 4 years (9).

In this report, CDC estimated prevalence of sealant use and untreated tooth decay among low-income $(\leq 185 \%$ of FPL, the qualification point for free/reduced-price meal program) and

\footnotetext{
${ }^{\dagger}$ http://www.thecommunityguide.org/about/aboutTF.html.
}

higher-income children aged 6-11 years using data from the recently released 2011-2014 NHANES and compared these data with data from the 1999-2004 NHANES. Estimates of tooth decay averted by providing sealants to children were also calculated.

\section{Methods}

To estimate current prevalences of sealant use and untreated decay for U.S. children aged 6-11 years, CDC combined the two most recent cycles of NHANES data (2011-2012 and 2013-2014). NHANES is a multistage probability sample of the noninstitutionalized U.S. population. ${ }^{\S}$ A child was classified as having sealants if at least one permanent tooth was assessed by a dentist to have a sealant present and as having untreated tooth decay if at least one permanent tooth had untreated decay.

Sealant use prevalence is presented for all children aged 6-11 years as well as for the following characteristics: sex; race/ethnicity; family income $\leq 185 \%$ of FPL versus $>185 \%$ of FPL; and highest level of education achieved by the head of household. Sealant use and untreated decay prevalence stratified by family income from NHANES 2011-2014 were compared with prevalences from NHANES 1999-2004. Sealant use and untreated decay status were assessed in the same way for both periods (1). Among children aged 7-11 years, the mean number of decayed and filled first molars (DFFM) was estimated for children with and without sealants, by family income status. For each income group, CDC used a published methodology to estimate the number of DFFM that would have occurred over 4 years if a child had not received sealants soon after eruption of the first molars (10). This value was multiplied by the prevented fraction (50\%) (G) to estimate averted DFFM per child attributable to sealants over 4 years. Estimates were standardized by year of age to the distribution in the 2000 U.S. Census (1).

Analyses were conducted using statistical software that accounts for the complex sample design of NHANES. Estimates from NHANES were obtained using the examination sample weights. All statistical tests were conducted at a 95\% significance level $(\mathrm{p}<0.05)$. Estimates with relative standard errors $>0.3$ were classified as unstable. To test whether sealant use prevalence varied with the characteristic of the child during 2011-2014, CDC used a chi-square test of independence. A t-test was used to determine whether changes in sealant use and decay prevalences between surveys or mean DFFM by sealant status and income were significant.

\footnotetext{
\$ http://www.cdc.gov/nchs/nhanes.htm.

9 Children aged 6 years were excluded because permanent first molars can erupt between ages 6 and 7 years (http://www.ada.org/ /media/ADA/Publications/ Files/patient_58.ashx).
} 


\section{Results}

Approximately $43 \%$ of children aged $6-11$ years received at least one dental sealant (Table 1 ), and sealant use prevalence among low-income children $(38.7 \%)$ was approximately 9.1 percentage points lower than among higher-income children $(47.8 \%)$. Sealant use prevalence was highest among non-Hispanic white children $(46.0 \%)$ and children from households where the head of household had more than a high school education (45.2\%) and lowest among non-Hispanic black children $(32.2 \%)$ and children from households where the head of household had a high school education (37.7\%).

From 1999-2004 to 2011-2014, overall prevalence of dental sealant use increased from $31.1 \%-43.6 \%$ (Table 2); increased by 16.2 percentage points to $38.7 \%$ (relative increase of $72.0 \%$ ) among low-income children; and increased by 8.8 percentage points (relative increase of 22.6\%) among higher-income children. Untreated decay decreased by 4.9 percentage points to $7.5 \%$ among low-income children and remained at about $4 \%$ among higher-income children.

Among children aged 7-11 years, the mean DFFM was significantly lower for both higher-income and low-income children with at least one sealant ( 0.19 and 0.29 , respectively) compared with children with no sealants $(0.52$ and 0.82 , respectively) (Table 3). The difference in mean DFFM between children with and without sealants was 0.33 and 0.52 for higher- and low-income children, respectively.

The estimated average annual probability of a permanent first molar developing decay, calculated with DFFM data by year of age for children aged 7-11 years, was 0.07 for lowincome children (data not shown). Because of unstable estimates, this probability was not estimated for higher-income children. Over 4 years, sealing all four permanent first molars of low-income children is estimated to prevent 0.52 DFFM per child (Table 4). The NHANES 2011-2014 dataset had sealant and income information for 1,371 low-income children aged 6-11 years, representing 10.5 million children nationally. Based on the proportion of low-income children without sealants in the NHANES dataset, it is estimated that approximately 6.5 million low-income children currently are not receiving the preventive benefits of dental sealants. Providing sealants to these low-income children would prevent 3.4 million DFFM over 4 years.

\section{Conclusions and Comments}

Increasing sealant use prevalence among low-income children could substantially reduce tooth decay. Because the benefits of sealants can last up to 9 years, and untreated decay prevalence is about twice as high for adolescents and young adults aged 12-19 years compared with younger children, it is likely
TABLE 1. Prevalence of dental sealants among children aged 6-11 years* by selected sociodemographic characteristics National Health and Nutrition Examination Survey, United States, 2011-2014

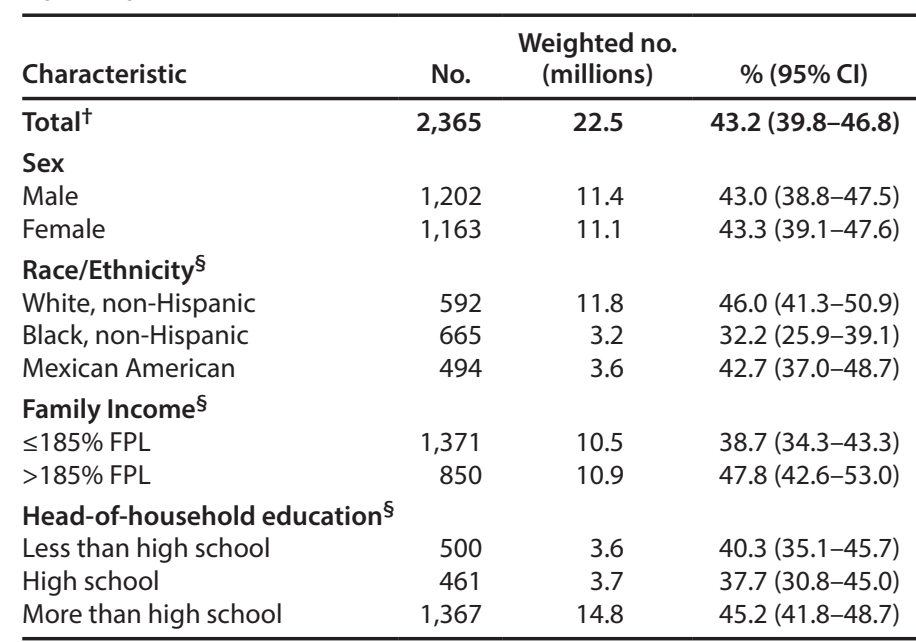

Abbreviations: $\mathrm{Cl}=$ confidence interval; $\mathrm{FPL}=$ federal poverty level.

* Total $\mathrm{N}=2,365$, representing 22,581,565 U.S. children; standardized by year of age, to age distribution in 2000 U.S. Census.

${ }^{+}$Includes 614 persons of other races (including multiracial persons), 144 with missing family income, and 37 who were missing/refused head-of-household education status.

$\S$ Chi-square test of independence significant at $p<0.05$.

that much of the pain and limitations in eating and learning associated with untreated decay could be prevented by timely application of sealants. In addition, providing sealants to these children could save societal resources. The systematic review of economic evaluations of SBSP conducted for the Task Force found that SBSP became cost-saving within 2 years of placing sealants (G). That review further found that delivering sealants to children at high risk for tooth decay could be cost-saving to Medicaid (9).

Data from the Agency for Healthcare Research and Quality indicate that less than half of children aged 6-11 years from families with incomes $<125 \%$ of the FPL had a past-year dental visit in 2013 (11). Sealants must be placed by a licensed dental professional with dental equipment; therefore, the lack of timely dental visits among low-income children might be an important reason that $60 \%$ lack sealants. Applying sealants in schools is an effective strategy to increase the prevalence of sealant application among children not accessing regular dental care, but few schools offer these programs. One survey of state oral health programs found that few states have SBSP in the majority of their high-need schools (i.e., $>50 \%$ of students participating in free/reduced meal program) (12). Financing is a major barrier to implementing and maintaining SBSP (13). Federal funding of state oral health programs is largely competitive and varies widely by state (13). Many state and local SBSP cover part of their expenses by Medicaid billing (13). Because labor accounts for about two thirds of SBSP costs (G), 
TABLE 2. Changes* in prevalence of dental sealants and untreated decay among children aged 6-11 years by family income - National Health and Nutrition Examination Survey, United States, 1999-2004 and 2011-2014

\begin{tabular}{|c|c|c|c|c|c|c|}
\hline \multirow[b]{2}{*}{ Prevalence } & \multicolumn{2}{|c|}{ 1999-2004 } & \multicolumn{2}{|c|}{ 2011-2014 } & \multicolumn{2}{|c|}{ Difference } \\
\hline & No. & $\%(95 \% \mathrm{Cl})$ & No. & $\%(95 \% \mathrm{Cl})$ & Percentage points & $(95 \% \mathrm{Cl})$ \\
\hline \multicolumn{7}{|l|}{ Sealants } \\
\hline All income groups & 2,789 & 31.1 (27.7 to 34.7$)$ & 2,221 & 43.6 (39.9 to 47.3 ) & $12.4^{\dagger}$ & (7.3 to 17.5$)$ \\
\hline$\leq 185 \% \mathrm{FPL}$ & 1,655 & 22.5 (18.6 to 26.9$)$ & 1,371 & 38.7 (34.3 to 43.3 ) & $16.2^{\dagger}$ & (10.1 to 22.4 ) \\
\hline$>185 \% \mathrm{FPL}$ & 1,134 & 39.0 (34.8 to 43.3 ) & 850 & 47.8 (42.6 to 53.0$)$ & $8.8^{\dagger, \S}$ & (2.1 to 15.6$)$ \\
\hline \multicolumn{7}{|l|}{ Untreated decay } \\
\hline All income groups & 2,854 & 7.6 (6.1 to 9.5$)$ & 2,284 & $5.9(4.8$ to 7.1$)$ & $-1.8^{\S}$ & $(-3.8$ to 0.3$)$ \\
\hline$\leq 185 \% \mathrm{FPL}$ & 1,692 & $12.4(9.9$ to 15.5$)$ & 1,410 & 7.5 (5.8 to 9.5$)$ & $-4.9^{\dagger, \S}$ & $(-8.3$ to -1.6$)$ \\
\hline$>185 \% \mathrm{FPL}$ & 1,162 & 3.5 ( 2.5 to 5.0$)$ & 874 & $4.3(3.0$ to 6.1$)$ & $0.8^{\S}$ & $(-1.2$ to 2.7$)$ \\
\hline
\end{tabular}

Abbreviations: $\mathrm{Cl}=$ confidence interval, $\mathrm{FPL}=$ federal poverty level.

* Standardized by year of age to age distribution in 2000 U.S. Census.

† Significant at $\mathrm{p}<0.05$ for $\mathrm{t}$-test.

$\S$ Relative standard error $>30 \%$.

TABLE 3. Mean number of decayed and filled first molars (DFFM) among children aged 7-11 years, ${ }^{*}$ by family income and sealant status National Health and Nutrition Examination Survey, United States, 2011-2014

\begin{tabular}{|c|c|c|c|c|c|c|c|c|}
\hline \multirow[b]{2}{*}{ Family income status } & \multicolumn{3}{|c|}{ With sealants } & \multicolumn{3}{|c|}{ No sealants } & \multicolumn{2}{|c|}{ Difference } \\
\hline & No. & DFFM & $(95 \% \mathrm{Cl})$ & No. & DFFM & $(95 \% \mathrm{Cl})$ & DFFM & $(95 \% \mathrm{Cl})$ \\
\hline$\leq 185 \% \mathrm{FPL}$ & 467 & 0.29 & $(0.23-0.36)$ & 698 & 0.82 & $(0.69-0.94)$ & $0.52^{\dagger}$ & $(0.37-0.67)$ \\
\hline$>185 \% \mathrm{FPL}$ & 362 & 0.19 & $(0.11-0.28)$ & 381 & 0.52 & $(0.35-0.69)$ & $0.33^{\dagger}$ & $(0.14-0.51)$ \\
\hline
\end{tabular}

* Children aged 6 years excluded because permanent first molar can erupt between ages 6 and 7 years.

${ }^{\dagger}$ Difference is significant at $\mathrm{p}<0.05$ for $\mathrm{t}$-test.

TABLE 4. Estimated mean number of new decayed and filled permanent first molars (DFFM) per child without sealants and DFFM averted with sealants for each year since placement and four-year total, among children aged 6-11 years from families with incomes $\leq 185 \%$ of federal poverty level — United States, 2011-2014

\begin{tabular}{lcc}
\hline $\begin{array}{l}\text { Years since } \\
\text { sealant placement }\end{array}$ & $\begin{array}{c}\text { DFFM per child } \\
\text { (without sealants) }\end{array}$ & $\begin{array}{c}\text { DFFM averted per child } \\
\text { (with sealants) }\end{array}$ \\
\hline 1 & 0.29 & 0.15 \\
2 & 0.27 & 0.13 \\
3 & 0.25 & 0.13 \\
4 & 0.23 & 0.12 \\
Total & 1.04 & $\mathbf{0 . 5 2}$ \\
\hline
\end{tabular}

revenues from Medicaid billing are more likely to cover costs if state policies allow dental hygienists or therapists to assess a child's need for and to place sealants without a dentist being present. For example, in South Carolina, SBSPs managed and staffed by dental hygienists deliver sealants in approximately $40 \%$ of high-need schools (12). These SBSP are primarily financed by Medicaid billing (13).

Another barrier to children receiving sealants in clinical and school settings is low health literacy. A study of California third graders found that their parent's health literacy and speaking English at home were strong predictors of the child having sealants (14). An Institute of Medicine report on increasing access to dental care among vulnerable and underserved populations also found that low oral health literacy was a major barrier to receiving preventive dental services (15).
The findings in this report are subject to at least one limitation. Because NHANES is not designed to provide estimates by year of age, a large number of estimates of DFFM by year of age and sealant status were unstable. However, among low-income children, all estimates of DFFM used to estimate the annual probability that an unsealed first molar developed decay were stable.

Children with sealants can still be at risk for tooth decay. Whereas fluoride can prevent decay in all teeth, sealants are primarily used to protect the back teeth from decay. Healthy behaviors documented to prevent decay include brushing with fluoride toothpaste and drinking fluoridated water or taking fluoride supplements if drinking water is not optimally fluoridated (2). Many of the studies included in the evidence informing the Task Force's recommendation for SBSP were conducted among children using fluoride toothpaste in communities with fluoridated water (G), suggesting that sealants provide additional benefit even among children receiving fluoride. Regularly scheduled dental visits are important to deliver preventive services (e.g., topical fluoride) and to monitor and control tooth decay and other oral conditions (2). SBSP can help caregivers of eligible children enroll in public insurance programs $(5,6)$ and can increase utilization of dental care by identifying tooth decay in children who are not regularly seen by a dentist and referring them for needed dental treatment.

\footnotetext{
${ }^{1}$ Division of Oral Health, National Center for Chronic Disease Prevention and Health Promotion, CDC; ${ }^{2}$ Dental public health consultant, Roswell, Georgia.

Corresponding author: Susan O. Griffin, sgriffin2@cdc.gov, 770-488-6054.
} 


\section{References}

1. Dye BA, Tan S, Smith V, et al. Trends in oral health status: United States, 1988-1994 and 1999-2004. Vital Health Stat 11 2007;(248):1-92.

2. US Department of Health and Human Services. Oral health in America: a report of the Surgeon General. Rockville, MD: US Department of Health and Human Services, National Institute of Dental and Craniofacial Research, National Institutes of Health, 2000. http://www.nidcr.nih.gov/ DataStatistics/SurgeonGeneral/Documents/hck1ocv.@www.surgeon. fullrpt.pdf

3. Lewis C, Stout J. Toothache in US children. Arch Pediatr Adolesc Med 2010;164:1059-63. http://dx.doi.org/10.1001/archpediatrics.2010.206

4. Jackson SL, Vann WF Jr, Kotch JB, Pahel BT, Lee JY. Impact of poor oral health on children's school attendance and performance. Am J Public Health 2011;101:1900-6. http://dx.doi.org/10.2105/AJPH.2010.200915.

5. Gooch BF, Griffin SO, Gray SK, et al. Preventing dental caries through school-based sealant programs: updated recommendations and reviews of evidence. J Am Dent Assoc 2009;140:1356-65. http://dx.doi. org/10.14219/jada.archive.2009.0070

6. Community Preventive Services Task Force. Guide to community preventive services. Preventing dental caries: school-based dental sealant delivery programs. US Department of Health and Human Services, Community Preventive Services Task Force; 2016. http://www. thecommunityguide.org/oral/schoolsealants.html

7. US Department of Health and Human Services. Healthy people 2020. Topics and objectives: oral health. Washington, DC: US Department of Health and Human Services; 2013. https://www.healthypeople.gov/2020/ topics-objectives/topic/oral-health?topicid $=32$

8. National Quality Forum. Oral health performance measurement: environmental scan, gap analysis and measure topics prioritizationtechnical report. Washington, DC: National Quality Forum; 2012. http:// www.qualityforum.org/Publications/2012/07/Oral_Health_ Performance_Measurement_Technical_Report.aspx
9. Griffin SO, Naavaal S, Scherrer CR, Patel M, Chattopadhyay S. Evaluation of school-based dental sealant programs: an updated community guide systematic economic review. Am J Prev Med. In press 2016.

10. Griffin SO, Jones K, Crespin M. Calculating averted caries attributable to school-based sealant programs with a minimal data set. J Public Health Dent 2014;74:202-9. http://dx.doi.org/10.1111/jphd.12047

11. Agency for Healthcare Research and Quality. Table 3: Dental services-mean and median expenses per person with expense and distribution of expenses by source of payment: United States, 2013. Rockville, MD: US Department of Health and Human Services, Agency for Healthcare Research and Quality; Medical Expenditure Panel Survey; 2013. https://meps.ahrq.gov/data_stats/quick_tables_ results.jsp? component $=1 \&$ subcomponent $=0 \&$ tableSeries $=1 \& y e$ ar $=-1 \&$ SearchMethod $=1 \&$ Action $=$ Search

12. The Pew Charitable Trusts. States stalled on dental sealant programs. Philadelphia, PA: The Pew Charitable Trusts; 2015. http:// www.pewtrusts.org/en/research-and-analysis/reports/2015/04/ states-stalled-on-dental-sealant-programs

13. Children's Dental Health Project. Dental sealants proven to prevent tooth decay: a look at issues impacting the delivery of state and local school-based sealant programs. Washington, DC: Children's Dental Health Project; 2014. https://www.cdhp.org/ resources/314-dental-sealants-proven-to-prevent-tooth-decay

14. Mejia GC, Weintraub JA, Cheng NF, et al. Language and literacy relate to lack of children's dental sealant use. Community Dent Oral Epidemiol 2011;39:318-24. http://dx.doi.org/10.1111/j.1600-0528.2010.00599.x

15. Institute of Medicine; National Research Council. Improving access to oral health care for vulnerable and underserved populations. Washington, DC: The National Academies Press; 2011. http://www.nationalacademies. $\mathrm{org} / \mathrm{hmd} /-/$ media/Files/Report\%20Files/2011/Improving-Accessto-Oral-Health-Care-for-Vulnerable-and-Underserved-Populations/ oralhealthaccess 2011 reportbrief.pdf 